\title{
Some considerations when preparing thickened tailings for shear strength testing in the laboratory from a slurry
}

\author{
D Reid The University of Western Australia, Australia \\ R Fanni Golder, Australia, and The University of Western Australia, Australia \\ AB Fourie The University of Western Australia, Australia
}

\begin{abstract}
Preparation of tailings in the laboratory to simulate the likely range of densities and resulting behaviour that will occur under load in situ is challenging. A number of issues of relevance include whether effects such as subaqueous deposition can be reproduced at all in the laboratory, and the potential importance of in situ layering of segregating tailings. These issues may have (thus far, largely unquantified) effects on mechanical behaviour in ways that are difficult to predict with element tests that are usually intentionally prepared homogeneously. Thickened tailings testing is conceptually easier, as issues such as segregation and the potential for subaqueous deposition are often not relevant. Despite this relative simplicity, a number of important considerations remain. While it is trivial to pour a thickened slurry into various forms of moulds or vessels to prepare for element testing, questions remain over whether the density that is reproduced will be relevant to in situ conditions. In particular, preparation of triaxial samples from thick slurries is particularly challenging as a number of steps are required to enable such samples to be 'free-standing', with each one of these steps potentially leading to slight disturbance and thus densification of the sample. Where such densification occurs, it would result in the element test results being non-conservative. This could have important implications with respect to expectations of the contractive (and potentially liquefiable) or dilative response of the tailings in situ.

To investigate these issues, a series of slurry-deposited triaxial tests was carried out using a non-segregating slurry. As test methods were refined during the program, the amount of disturbance applied to the specimen was reduced. However, comparison of the triaxial tests to slurry consolidometer tests indicated that, regardless of efforts made, the triaxial tests achieved denser states at a given amount of consolidation stress. This was found to be the case using any conceivable range of assumed geostatic stress ratio to interpret the slurry consolidometer results. This outcome is speculated to be a result of the quiescent conditions used in the preparation of a slurry consolidometer specimen, which only requires pouring and then application of vertical load, first using weights, then a load frame. The implications of the increased density seen in triaxial tests compared to the likely more realistic value seen from the slurry consolidometer are discussed. Alternative preparation methods to target this looser density range are briefly discussed.
\end{abstract}

Keywords: laboratory testing, liquefaction, thickened tailings

\section{Introduction}

Preparing element tests of tailings in the laboratory in a condition representative of in situ conditions is a challenge that the geotechnical testing community has faced for decades (Høeg et al. 2000; Chang et al. 2011). It is also an area of particular importance to the design of thickened tailings deposits, as prior to deposition beginning it is often important to provide indicators of likely in situ behaviour after actual deposition - for example, whether the material is expected to be in a contractive or dilative state, and the peak and undrained shear strengths should the material be contractive (e.g. Reid \& Fourie 2014).

One advantage of the laboratory characterisation of thickened tailings, compared to conventional deposition, is that segregation is less likely owing to the increased slurry density. This is in general considered a positive 
aspect with respect to laboratory element tests where specimens must be prepared in a non-segregated condition in order to be considered an 'element'. Procedures to prepare and test intentionally segregated samples are immature and lack consensus (e.g. Baziar \& Dobry 1995), and therefore avoidance of this issue simplifies element testing of thickened tailings. Alternatively, even in the narrow context of non-segregating slurries, there is limited evidence as to what laboratory preparation techniques are likely to reproduce the in situ state and density. Further, the triaxial test - the most important and common element test used in geotechnical engineering - requires special considerations and techniques to prepare specimens of predominately silt, low plasticity materials (i.e. many tailings) from a slurry. The implications of the inherent difficulties in preparing triaxial specimens from a slurry on the prediction of consolidated density, and thus shearing behaviour, is not well quantified.

This paper outlines a series of tests on a gold tailings using both a slurry consolidometer and anisotropically consolidated triaxial tests. The purpose of these tests was to observe the range of densities achievable, with particular focus on how similar the two tests would predict in situ density, with particular focus on whether they would predict contractive or dilative behaviour. The gold tailings used has been thoroughly characterised in a previous study to obtain the critical state line (CSL) and undrained strengths of loose moist tamped samples, which provides reference data for the tests carried out in this study.

\section{Experimental program}

\subsection{Materials}

The gold tailings used were sourced from the surface of an existing Australian tailings storage facility (TSF), retrieved from the same location as the materials used to carry out a recent CSL round robin program (Reid et al. 2021) and calibration chamber testing (Ayala et al. 2020). As most of that batch of material was used in these cited studies, another batch of near-identical material was prepared to carry out further investigation of the effect of laboratory preparation on shearing behaviour, of which this paper forms a part. Index test data for the materials described is provided in Tables 1 and 2, while state diagrams showing the CSLs from this and previous studies are presented in Figure 1.

Table 1 Index properties of gold tailings tested in this study and related materials

\begin{tabular}{|c|c|c|}
\hline Property & $\begin{array}{l}\text { Gold tailings - CSL round robin } \\
\text { (Reid et al. 2020) and calibration } \\
\text { chamber testing (Ayala et al. 2020) }\end{array}$ & $\begin{array}{l}\text { Gold tailings - further fabric } \\
\text { investigation (Reid et al. 2021) } \\
\text { and this study }\end{array}$ \\
\hline Specific gravity $\left(G_{s}\right)$ & 2.78 & \multirow{4}{*}{$\begin{array}{l}\text { Not determined, as gradation } \\
\text { essentially identical to round } \\
\text { robin batch }\end{array}$} \\
\hline Liquid limit $w_{L}$ & 18 & \\
\hline Plastic limit $w_{\mathrm{P}}$ & 16 & \\
\hline Plasticity index & 2 & \\
\hline$\%<75 \mu \mathrm{m}$ & 59 & 58 \\
\hline$\%<38 \mu \mathrm{m}$ & 43 & \multirow[t]{2}{*}{44} \\
\hline $\mathrm{D}_{90} / \mathrm{D}_{50} / \mathrm{D}_{10}(\mu \mathrm{m})$ & $250 / 50 / 19$ & \\
\hline $\begin{array}{l}\text { Standard maximum } \\
\text { dry density (SMDD) }\end{array}$ & $1.87 \mathrm{t} / \mathrm{m}^{3}$ & \multirow{2}{*}{$\begin{array}{l}\text { Not determined, as gradation } \\
\text { essentially identical to round } \\
\text { robin batch }\end{array}$} \\
\hline $\begin{array}{l}\text { Optimum water } \\
\text { content }\end{array}$ & $13 \%$ & \\
\hline
\end{tabular}


Table 2 Tailings mineralogical information (after Ayala et al. 2020)

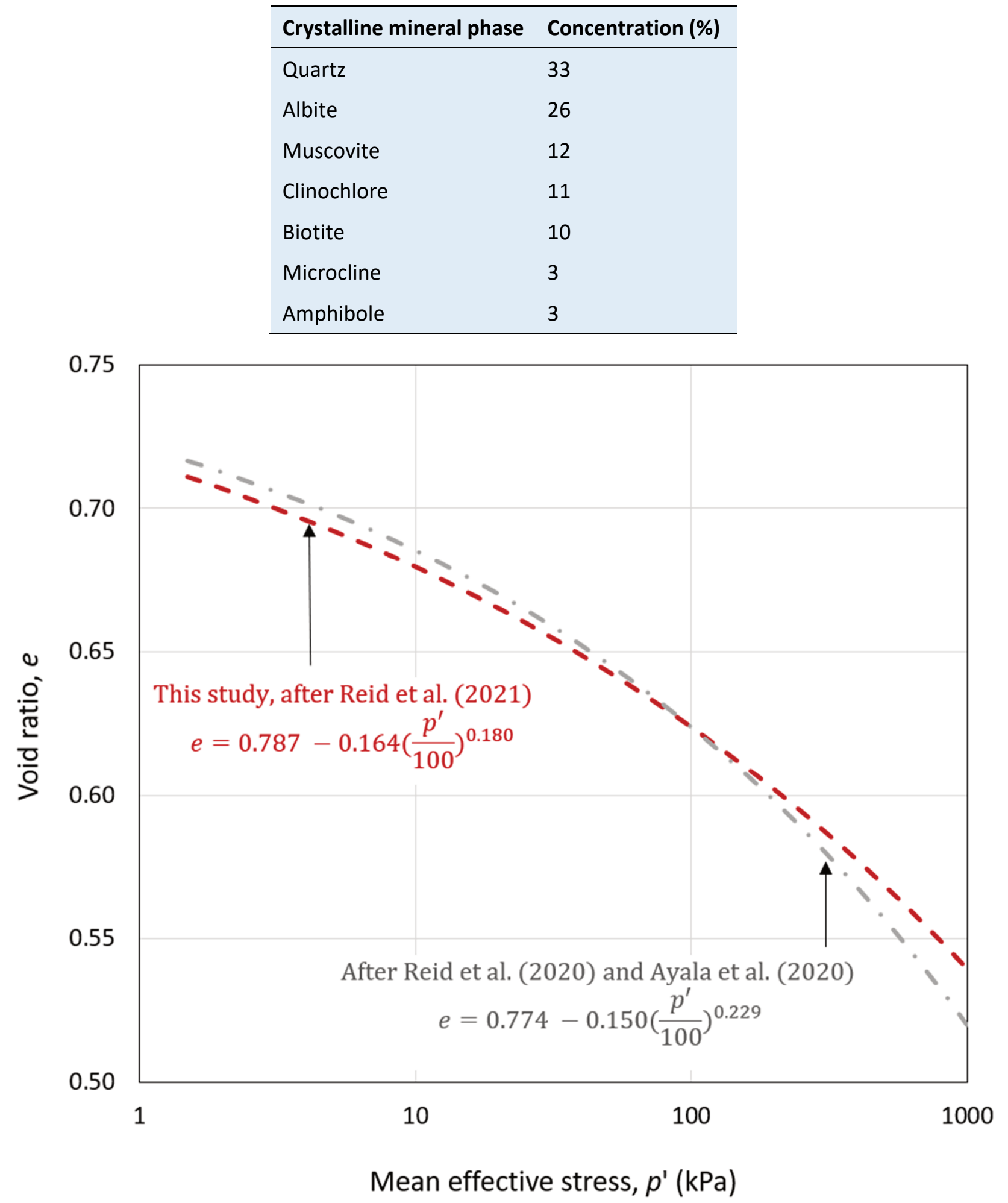

Figure 1 Critical state line and state diagram of gold tailings used in this study and similar material used for other related studies 
For the current study, finding the range of slurry gravimetric water content (GWC) that could be used to produce non-segregating 'pourable' slurries was first carried out. The lowest GWC that could be feasibly poured in a uniform manner was found to be about $28 \%$ GWC. To find the limit for segregation of the material, a series of small settling tests were carried out at a range of GWC, then the top and bottom of the samples after settling were wet sieved over a $75 \mu \mathrm{m}$ sieve to determine if segregation had occurred, based on a technique adopted by Reid \& Fanni (2020). This indicated that slurries at a GWC greater than $50 \%$ are at risk of undergoing segregation during pouring and subsequent settling.

\subsection{Slurry consolidometer test methods}

Slurry consolidometer tests were carried out in a $140 \mathrm{~mm}$ internal diameter acrylic column. A loading cap with embedded filter stone was used to apply loads, with first small weights and then a load frame used to consolidate the specimen to a vertical effective stress of $400 \mathrm{kPa}$. A constant rate of loading method was applied to the specimens between 20 and $400 \mathrm{kPa}$, to be generally consistent with the methods of anisotropic consolidation used subsequently in triaxial tests. Pore pressure was monitored at the base of the specimen, however negligible excess pore pressure was detected at the selected loading rate of $2 \mathrm{kPa} /$ minute owing to the rapid rate of consolidation of the material. Importantly, once the slurry was poured into the testing vessel, no further manipulation of the apparatus is required - in other words, slight densification of the specimen on the basis of post-pouring interaction and disturbance is unlikely.

Two tests were carried out, at 28 and $45 \%$ GWC respectively, to assess if initial GWC for this material affected subsequent consolidated densities, as is common to many slurries (e.g. Reid \& Fourie 2015). As the results did indicate this effect was present in these tailings, all subsequent triaxial tests were prepared from slurries at $45 \%$ GWC in an attempt to produce specimens as loose as possible (from a non-segregating slurry, at least) for subsequent shearing. Void ratio of the samples was obtained through the volume of the specimen during each load stage and the dry mass of solids obtained through oven drying at the end of the test. Measurements of sample height were made directly to the loading top cap, to avoid errors relating from compressibility of the load frame.

\subsection{Triaxial test methods}

A wide variety of methods have been employed to prepare specimens of sands or silts from a slurry - usually referred to as slurry deposition (SD). These include methods where sands with a relatively low proportion of fines (typically $<30 \%$ ) are de-aired, mixed, and deposited together into a triaxial split mould (Kuerbis \& Vaid 1988; Carraro \& Prezzi 2008). Alternatively, the term SD is also used for methods where relatively thick non-segregating soils predominately consisting of silt-sized particles are poured into a split mould and loaded one dimensionally directly in the mould prior to being dismantled later. Given the consistency of the gold tailings used in this study (i.e. predominately silt) the latter technique was adopted.

The specific methods were based on those outlined by Reid \& Fanni (2020), which involves some modifications and complications compared to typical silt SD owing to the use of oversized lubricated end platens, which are included to promote more uniform stresses and strains during the test. The preparation involved the following steps:

1. The split mould is lined with a membrane sleeved over the bottom platen as with most triaxial testing. An extension collar was then added to enable an initially taller specimen to be poured and loaded such that it eventually reached the target height required by the primary split mould (which incorporated features to enable use of oversized lubricated end platens, therefore requiring a consistent initial specimen height).

2. A slurry at $45 \%$ GWC is poured into the split mould, then the slurry is gently agitated by stirring to remove large, entrapped bubbles.

3. Filter paper and filter stones are placed on the slurry, followed by an increasing vertical load in an attempt to produce a specimen height consistent with the split mould requirements. 
4. Two different approaches were taken to place the specimen top cap, in efforts to improve the process and reduce disturbance of the specimen:

a. Test TX1: After consolidation under $30 \mathrm{kPa}$ vertical load, the extension collar was removed, and sample inspected. As the consolidated sample was too high for the split mould arrangement, the extra material was removed by trimming. Then the top cap was placed onto the specimen.

b. Tests TX2 and TX3: Owing to concerns regarding the disturbance resulting from trimming, the remaining tests used an increased load $(\sim 100 \mathrm{kPa})$ that was selected to both bring the consolidated specimen height to a level such that trimming was unnecessary, and as it appeared likely that vertical consolidation under such stresses produced a specimen less susceptible to densification disturbance in subsequent stages of the preparation process.

5. A suction of $20 \mathrm{kPa}$ was applied to both ends of the specimen using the back pressure pump. A small $5 \mathrm{kPa}$ vertical load was kept on the top cap to continue to force the specimen and membrane against the split mould walls. The authors have found that without this small load during suction application, it is possible for the membrane and specimen to 'pull in' in some locations creating an irregular non-cylindrical specimen on mould removal.

6. Once the specimen reached equilibrium under the $20 \mathrm{kPa}$ suction, the split mould was carefully removed. Initial specimen dimensions were then measured.

It is emphasised that the process described above requires a number of instances where the specimen must be manipulated - removal of extension collars, placement of top caps, and removal of split moulds. For a saturated low plasticity sample, any disturbance of this type is likely to result in densification of the specimen. Further, at least one unload-reload loop is necessary, owing to the requirement to remove the one dimensional consolidation weights, place top cap, and establish a suction of $20 \mathrm{kPa}$ to enable a free-standing specimen. This unload-reload loop is itself likely to further densify the specimen.

After specimen preparation, test methods followed relatively common triaxial techniques. The cell and back pressure were both ramped to promote improved saturation quality of the specimen, while maintaining $20 \mathrm{kPa}$ effective stress (i.e. the difference between cell and back pressure). Skempton's $B$ value was then checked, which, if higher than $96 \%$, was taken as sufficient, whereas if a lower value was obtained, a further increase in back and cell pressure was carried out. Once saturated in this manner, anisotropic consolidation was carried out from an initial isotropic $20 \mathrm{kPa}$ condition to a final state with $\sigma^{\prime}{ }_{1}=300 \mathrm{kPa}, \sigma^{\prime}{ }_{3}=150 \mathrm{kPa}$ and $p^{\prime}=200 \mathrm{kPa}$. This condition was selected as $K_{0}$-triaxial tests carried out in a parallel study indicated a value of about 0.5 for normally consolidated laboratory specimens, and to be consistent with a large series of moist tamped tests carried out by Reid et al. (2021) that adopted the same value. Anisotropic consolidation was used as this closely parallels the one dimensional consolidation that occurs in the slurry consolidometer.

Consolidation ramping was carried out over a period of three hours, with the specimen left at the final consolidation stresses for an additional one hour. At the end of this time, volume change was seen to be negligible and undrained shearing was then carried out at an approximate rate of $4 \%$ axial strain per hour. After shearing, end-of-test soil freezing was used to provide the most accurate practicable measure of void ratio (Sladen \& Handforth 1987; Reid et al. 2020) which involves sealing the specimen, freezing, then measuring GWC through oven drying of the initially frozen specimen. 


\section{$3 \quad$ Results}

\subsection{Slurry consolidometer results}

The results of the two slurry consolidometer tests are first presented as Figure 2, as void ratio versus vertical effective stress. As can be seen, the $45 \%$ GWC specimen achieves a looser state across the range of vertical effective stresses used in the test. This is consistent with many observations of the effect of slurry GWC on resulting consolidation behaviour (e.g. Reid \& Fourie 2015). As noted previously, on the basis of this observation all triaxial tests carried out in this study were prepared from $45 \%$ GWC in order to target as loose a density as practicable.

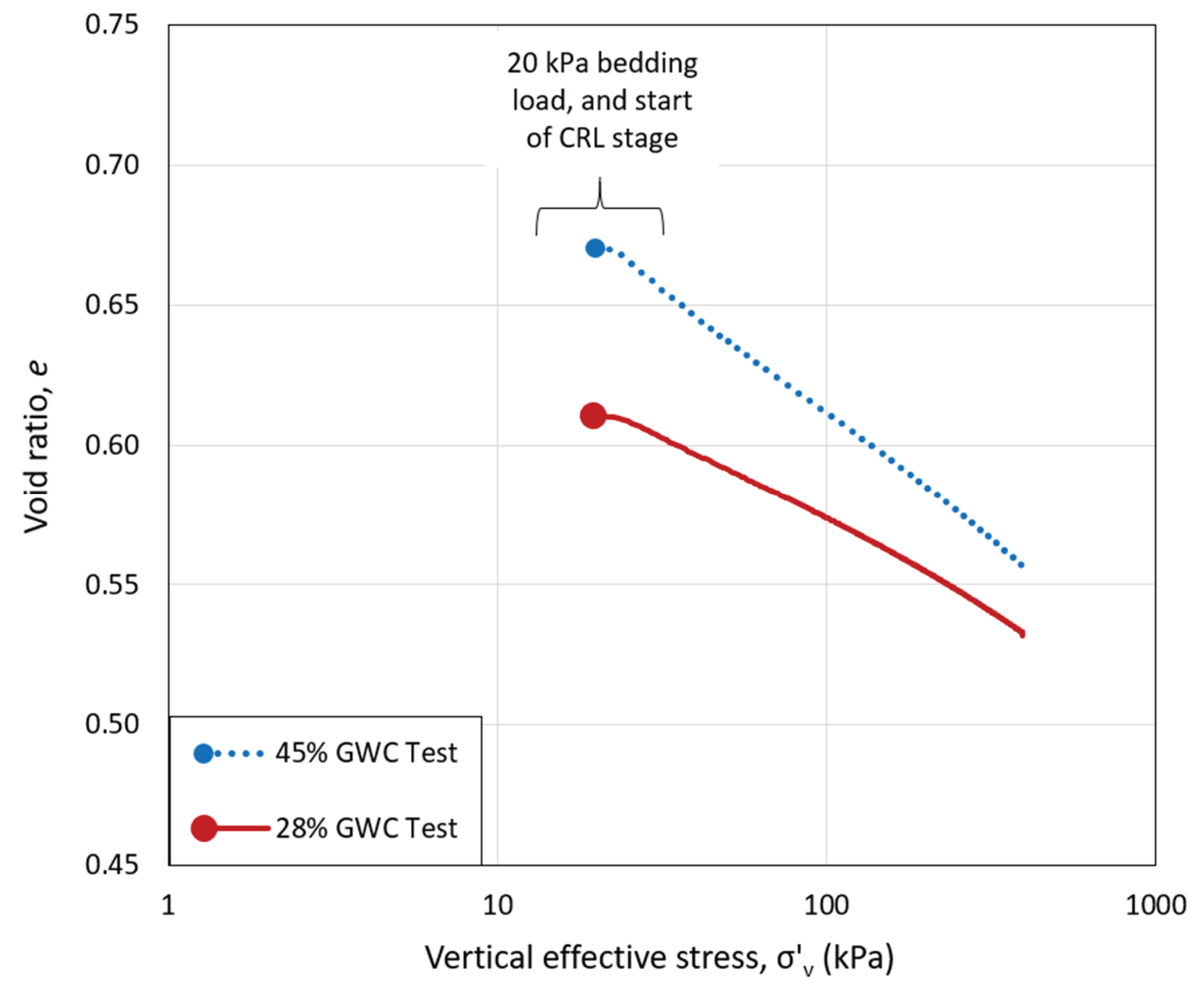

Figure 2 Results of two slurry consolidometer tests

\subsection{Triaxial test results}

Triaxial tests results are presented in Figure 3 as void ratio versus mean effective stress, with the CSL previously measured for these tailings included for comparison (Reid et al. 2021). The specimens are all seen to be dense of the CSL to varying degrees. It is also seen that the improved process employed in tests TX2 and TX3 has led to less disturbance and therefore a looser state than test TX1 that included trimming of the sample surface and lower initial vertical load application. 


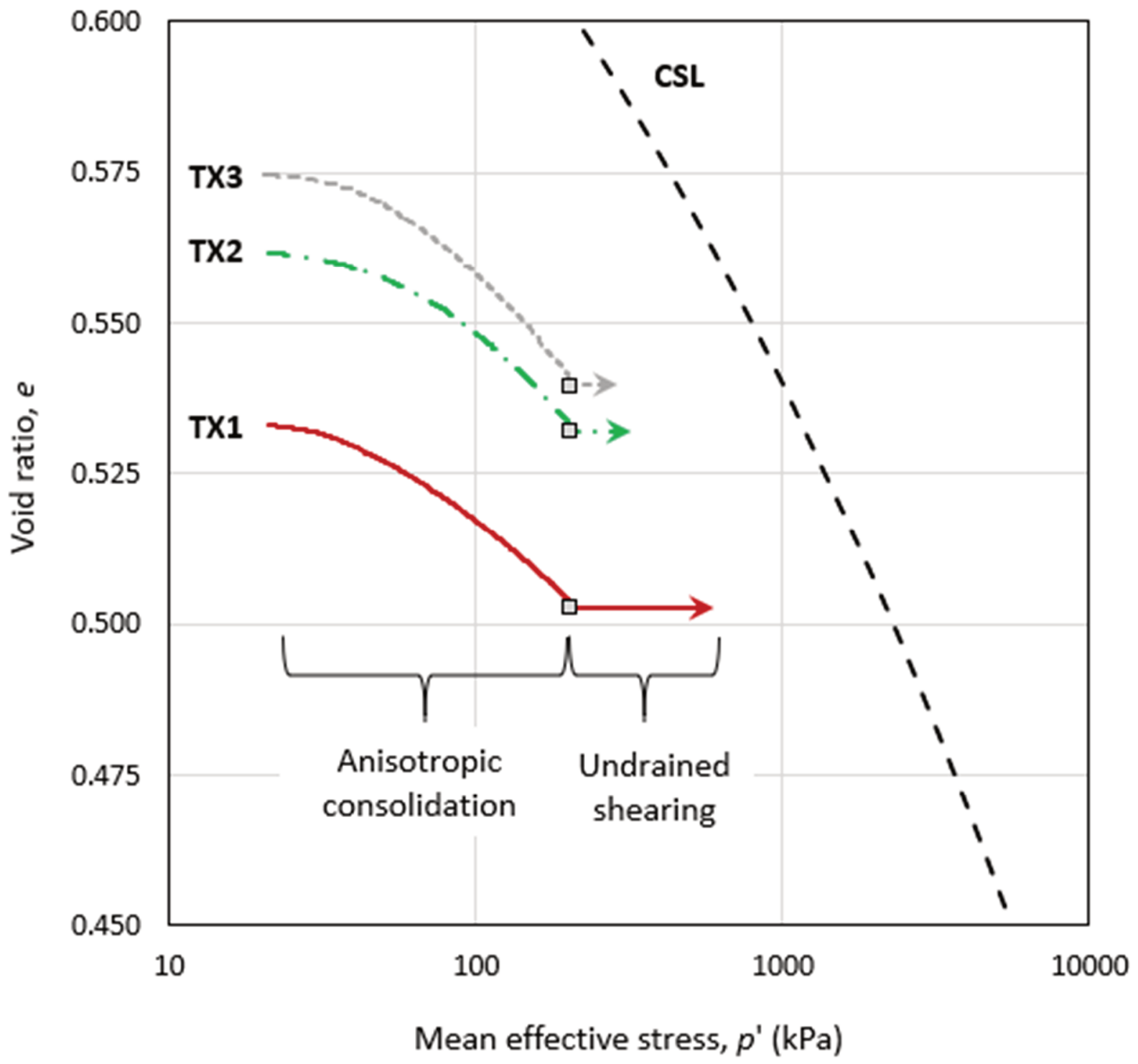

Figure 3 Consolidation and shearing behaviour of the triaxial specimens

Shearing behaviour of the specimens is presented in Figure 4 as a Cambridge plot. All of the tests exhibited a small amount of contraction at small strain followed by a strongly dilative response at higher strain. This is consistent with each of the specimens being dense of the reference CSL. Importantly, these test results - if obtained in isolation - would result in the conclusion that this tailings, if deposited at $45 \%$ GWC, would lead to a dilative response in situ. In other words, there would be negligible risk of brittle strength loss and flow liquefaction. 


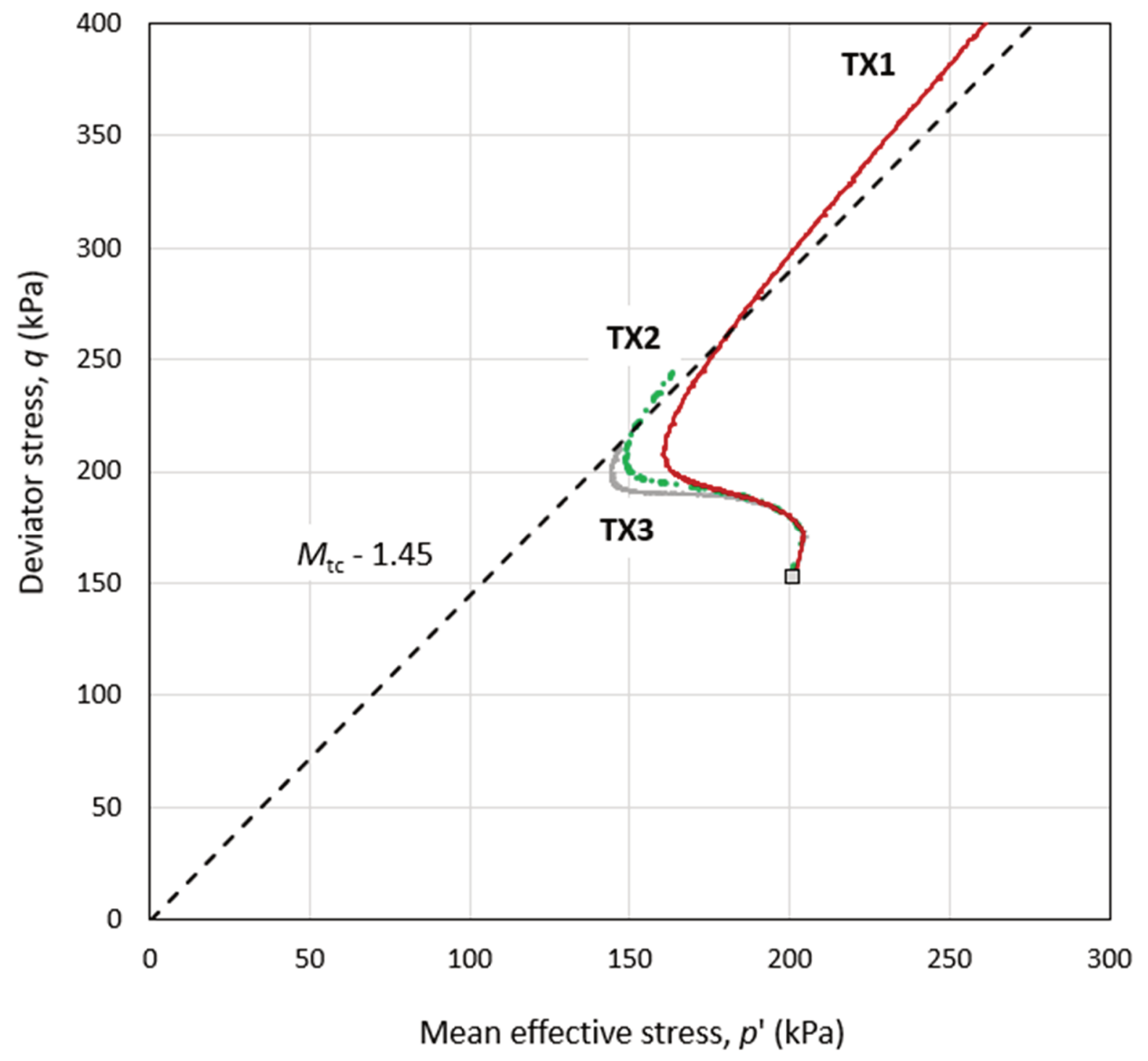

Figure 4 Cambridge plot presentation of triaxial shearing behaviour

\subsection{Synthesis of slurry consolidometer and triaxial test results}

The results of the slurry consolidometer and triaxial tests are synthesised in Figure 6 as a state diagram with stress in terms of mean effective stress $\left(p^{\prime}\right)$. For the purpose of plotting the slurry consolidometer results, where only vertical effective stress is measured, a $K_{0}$ of 0.5 was assumed for the calculation of mean effective stress. This is consistent with $K_{0}$-type tests carried out in parallel to the current study on the material, and expectations of the behaviour of virgin-consolidated reconstituted specimens of a sandy-silt tailings. It is also noted that any plausible estimate of $K_{0}$ used for the purpose of the comparison would not affect the conclusions drawn.

The comparison in Figure 5 highlights the looser densities seen in the slurry consolidometer test across a wide range of stresses where the comparison can be made. The difference is greatest at lower stresses, which is consistent with the requirement to carry out unload-reload loops when preparing SD triaxial specimens in other words, at low effective stresses the consolidation data shown for the SD triaxials does not represent a normally consolidated condition in the early stages of the test, owing to previous steps in the sample preparation process. Importantly, however, the difference in the consolidated densities extends to higher stresses where the SD triaxials will be normally consolidated. This comparison supports the hypothesis that small amounts of disturbance that occur during preparation of the SD triaxials is leading to densification, and thus potentially non-conservative estimates of density and shearing response. 


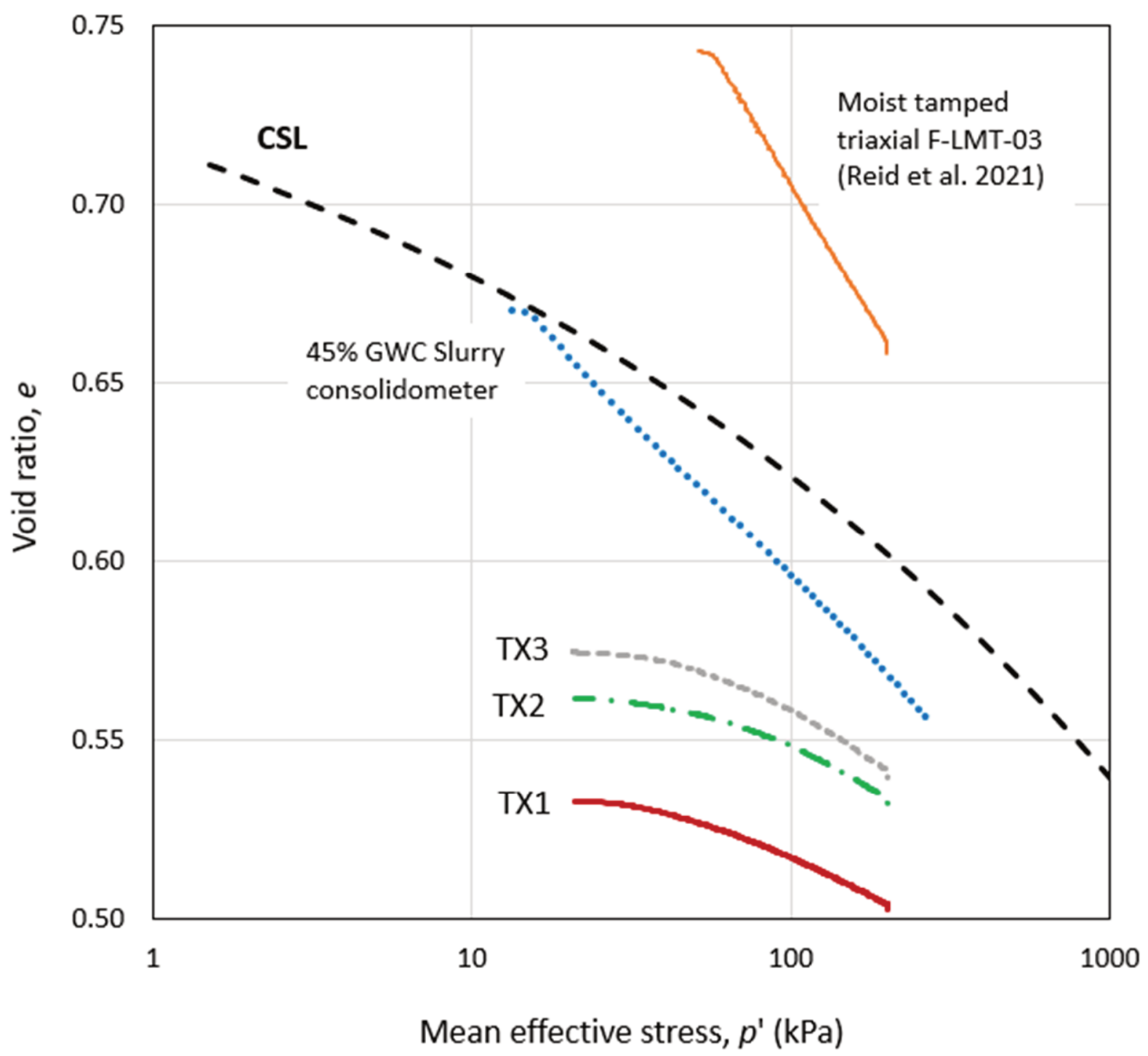

Figure 5 Synthesis of slurry consolidometer and SD triaxial consolidation data

It is interesting to note that the tailings tested appears to exist within an infinite range of normally consolidated lines (NCL), which is consistent with the idealisation purported by several researchers (i.e. Ishihara et al. 1975; Jefferies \& Been 2000, 2015). Also included in Figure 5 is the consolidation path of a moist tamped triaxial carried out by Reid et al. (2021) as part of the initial characterisation of the gold tailings. This test again demonstrates the existence of a wide range of possible NCLs and the much looser accessible densities of the material under different preparation methods. As for the relevance of this moist tamped test, it could certainly be argued that a non-segregating subaerially deposited slurry is unlikely to achieve such loose states in situ - see, for example, interpretation of in situ states for the Osborne TSF presented by Reid \& Fourie (2015) on the basis of data presented by McPhail et al. (2004), which would support that argument. However, field scenarios where such loose states could occur may include filtered tailings placement without compaction, which resembles moist tamping in many ways, or subaqueous pluviation of the tailings in quiescent water. Although clearly a thickened tailings deposit would seek to avoid deposition into water, it is not uncommon for perimeter raising requirements of some thickened deposits to result in perimeter wall construction and raising, with supernatant water then reporting to channels and ponds that form against the wall. Whatever the mechanism, it is clear that no slurry-based sample preparation technique, regardless of the measures taken to minimise disturbance during preparation, could be prepared to loose states such as may result from uncompacted placement on a filter deposit or quiescent subaqueous deposition, with this issue as it related to subaqueous deposition having received the most study and discussion (Shuttle \& Cunning 2007; Reid \& Jefferies 2017, 2018; Reid et al. 2018, 2019; Reid 2021). 


\section{$4 \quad$ Benchmarking from other data}

\subsection{Other examples of SD in literature}

The consolidation behaviour of the SD triaxial specimens in the current study resulted in a strongly dilative shearing response. However, a number of laboratory-specific variations to the SD exist, and the production of samples with a dilative state may not be a universal outcome to SD procedures. Therefore, it is useful to examine other published examples of SD preparation on low plasticity predominately silt soils or tailings, particularly whether the shearing response was dilative or not. A list of such works is presented in Table 3 , with the reference and tested material information provided. This list was specific to the form of SD used in the current study on predominately silt materials, where vertical loading is required within the split mould to produce a sufficiently competent sample to be free-standing - distinct from other forms of SD on soils that are predominantly sand (Kuerbis \& Vaid 1988; Carraro \& Prezzi 2008). For each of the test programs listed in Table 3, a dilative response was seen in the tested samples. This, therefore, tentatively indicates that the various forms of SD currently employed for silts are all likely to result in a dilative response - a response which may not be consistent with in situ conditions in some cases.

Table 3 Other studies on triaxial testing of low plasticity silts prepared using SD methods

\begin{tabular}{lllll}
\hline Reference & Soil type & \% $<75 \boldsymbol{\mu m}$ & $\begin{array}{l}\text { \% silt-sized } \\
(\mathbf{2}-75 \boldsymbol{\mu m})\end{array}$ & $\begin{array}{l}\text { Plasticity } \\
\text { index (\%) }\end{array}$ \\
\hline $\begin{array}{l}\text { Hyde et al. (2006) } \\
\text { Donahue et al. (2008) }\end{array}$ & Powdered limestone & 88 & 69 & 6 \\
& $\begin{array}{l}\text { Natural silts sampled from } \\
\text { Adapazari, Turkey - 'soil G' }\end{array}$ & 77 & 62 & 10 \\
Wang et al. (2011) & Mississippi River valley silt & 99 & 86 & 6 \\
Reid (2019) & Thickened tailings & 81 & 63 & $0-5$ \\
\hline
\end{tabular}

We note that one work excluded from the list in Table 3 is that of Chang et al. (2011), who were able to prepare SD specimens that exhibited a contractive response for a low plasticity silt tailings. However, it is noted that as part of their SD preparation process, Chang et al. (2011) added a flocculant to the tailings to enable looser densities to be achieved. This then raises important questions about the applicability of the results to an unflocculated thickened tailings, as there is clear evidence that addition of flocculants to slurry-prepared specimens is likely to affect both mechanical properties and potentially the CSL (Mao \& Fahey 1999; Reid \& Fourie 2016, 2017, 2018a, 2018b). Further study of these aspects would be useful, as if flocculants can be used to achieve looser states while creating a specimen representative of in situ, this would be a major advantage for tailings laboratory testing works.

\subsection{Comparison to in situ densities}

An implicit hypothesis of the current work is that the slurry consolidometer tests, which can be prepared with negligible disturbance, are more representative of what may occur in situ for thickened tailings deposition - otherwise the increased density of the SD triaxials would not be problematic with respect to inferring in situ conditions from element tests. However, actual in situ data is necessary to confirm this. The data presented for the Osborne TSF (McPhail et al. 2004) was previously mentioned as supporting evidence that non-segregating thickened slurries that undergo subaerial deposition are unlikely to result in the very loose states that can be achieved with moist tamping - a conclusion that is also supported by various reviews of in situ data when compared to deposition type (Reid \& Jefferies 2017, 2018). However, as most of these examples rely on screening-level in situ test interpretation, they are unsuitable to attempt to compare in situ behaviour from the slurry consolidometer and SD triaxial behaviour presented in this study - the in situ data in these cases is simply insufficiently accurate to allow such subtle distinctions as seen here for laboratory element tests to be critically examined. 
Reid \& Fanni (2020) carried out a detailed assessment of a series of high-quality block samples recovered from the surface of a thickened, non-segregating iron ore TSF. Tests on intact specimens trimmed from the blocks were carried out, which arguably form the most representative measurement possible of expected in situ density and subsequent consolidation behaviour. These intact specimens were then compared to reconstituted samples prepared using both moist tamping and SD of a similar form to that employed in the current study. Importantly, gradation analysis of the block samples taken from site indicated they were largely homogenous, enabling a more rational comparison of in situ and reconstituted specimens than is often possible (e.g. Bazar \& Dobry 1995).

A synthesis of the results presented by Reid \& Fanni (2020) is presented in Figure 6 . The CSL measured using moist tamped (MT) specimens is shown along with the range of consolidated densities achieved from 10 tests on intact specimens trimmed from blocks. These are seen to 'straddle' the CSL, exactly consistent with the observations of Reid \& Jefferies (2018) with respect to the likely states of such deposits. Conversely, the SD triaxials carried out achieve significantly denser states than appear realistic for in situ conditions. This, therefore, strongly suggests that the difficult-to-avoid disturbance densification that occurs when preparing SD triaxials of predominately silt tailings will result in higher densities than in situ, with important design implications if this discrepancy is not recognised.

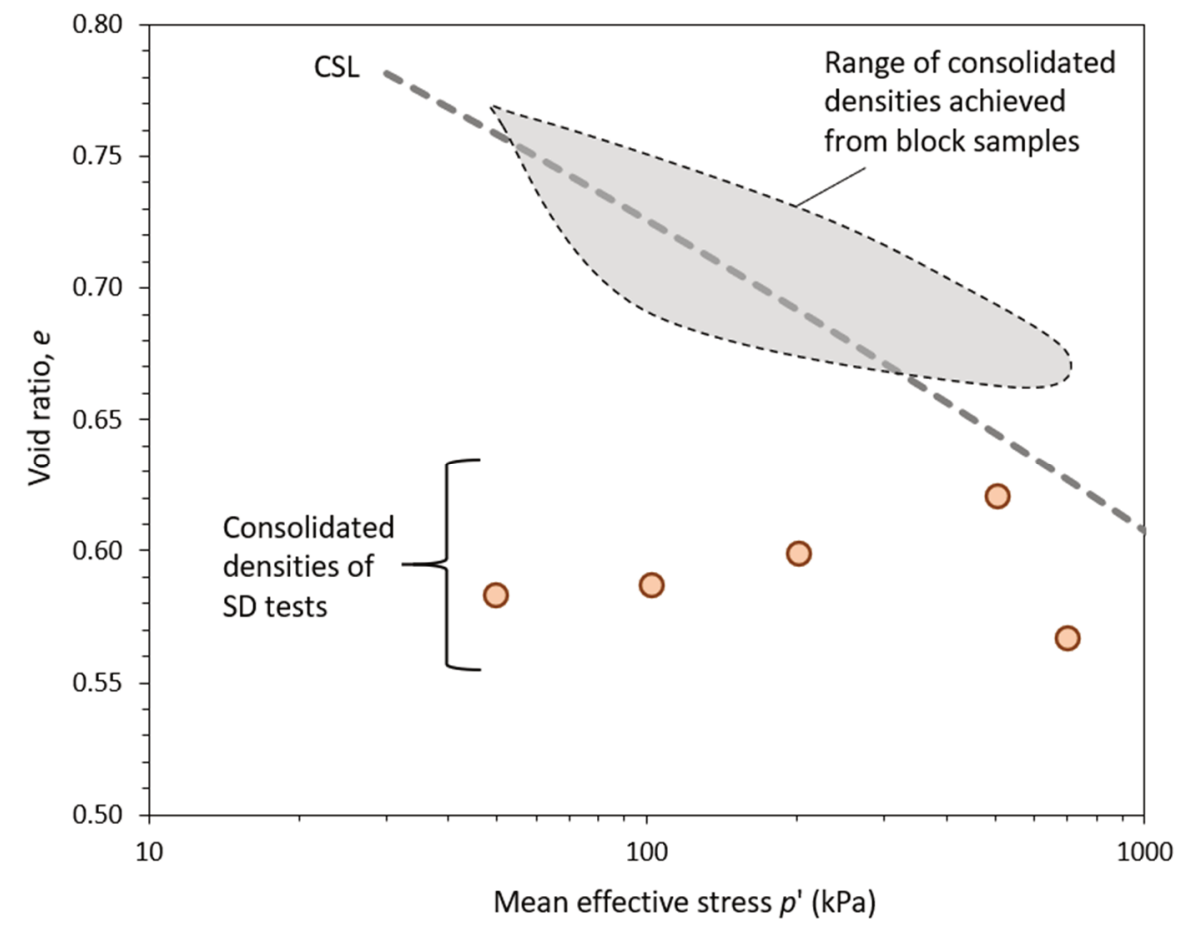

Figure 6 Comparison of SD-accessible densities to those measured from high-quality block samples (after Reid \& Fanni 2020)

\section{Conclusions}

A series of slurry consolidometer and SD triaxial specimens were carried out and compared for assessing the range of in situ densities achieved with the two testing devices and inherent preparation methods, and the potential relevance of these densities to in situ conditions of the subaerially deposited thickened tailings beach. These element tests were then compared to the results of other such studies on low plasticity predominately silt tailings and intact specimens trimmed from high-quality block samples. The following conclusions could be drawn from the results of this work:

- SD triaxial preparation methods appear to result in some unavoidable disturbances during preparation which, possibly in combination with the necessity for unload-reload loops and subsequent top cap placement, leads to higher consolidated densities than do slurry consolidometers that can be prepared and loaded without such activities and disturbances. 
- The SD triaxial prepared samples exhibited a strongly dilative response owing to the consolidated densities, consistent with their state with respect to the measured CSL for the material.

- It appears that most previous workers who adopted SD techniques for triaxial specimens also observed a dilative response during shearing, consistent with the observations of the current study.

- Comparison of the slurry consolidometer and SD triaxial densities of the current study to in situ measurements on high-quality block samples of similar materials suggests that the SD triaxials produce higher densities than are likely to occur in situ, and thus that the inferred undrained response from such tests is non-conservative.

\section{Acknowledgement}

This work forms part of TAILLIQ (Tailings Liquefaction), which is an Australian Research Council (ARC) Linkage Project supported by financial and in-kind contributions from Anglo American, BHP, Freeport-McMoRan, Newmont, Rio Tinto, and Teck. The TAILLIQ project is being carried out at The University of New South Wales (UNSW), The University of South Australia, The University of Western Australia (lead university), and The University of Wollongong.

\section{References}

Ayala, J, Fourie, A \& Reid, D 2020, 'Cone penetration testing on silty tailings using a new small calibration chamber', Géotechnique Letters, vol. 10, no. 4, pp. 492-497.

Baziar, MH \& Dobry, R 1995, 'Residual strength and large deformation potential of loose silty sands', Journal of Geotechnical Engineering, vol. 121, no. 12, pp. 896-906.

Carraro, JAH \& Prezzi, M 2008, 'A new slurry-based method of preparing specimens of sand containing fines', Geotechnical Testing Journal, vol. 31, no. 1, pp. 1-11.

Chang, N, Heymann, G \& Clayton, C 2011, 'The effect of fabric on the behaviour of gold tailings', Géotechnique, vol. 61, pp. 187-197.

Donahue, J, Bray, J \& Riemer, M 2008, Liquefaction Susceptibility, Resistance, and Response of Silty and Clayey Soils, University of California, Berkeley.

Høeg, K, Dyvik, R \& Sandbækken, G 2000, 'Strength of undisturbed versus reconstituted silt and silty sand specimens', Journal of Geotechnical and Geoenvironmental Engineering, vol. 126, pp. 606-617.

Hyde, AFL, Higuchi, T \& Yasuhara, K 2006, 'Liquefaction, cyclic mobility, and failure of silt', Journal of Geotechnical and Geoenvironmental Engineering, vol. 132, no. 6, pp. 716-735.

Ishihara, K, Tatsuoka, F \& Yasuda, S 1975, 'Undrained deformation and liquefaction of sand under cyclic stresses', Soils and Foundations, vol. 15, no. 1, pp. 29-44.

Jefferies, MG \& Been, K 2015, Soil Liquefaction: A Critical State Approach, 2nd edn, CRC Press, Boca Raton.

Jefferies, MG \& Been, K 2000, 'Implications for critical state theory from isotropic compression of sand', Géotechnique, vol. 50, no. 4, pp. 419-429.

Kuerbis, R \& Vaid, YP 1988, 'Sand samples preparation - the slurry deposition method', Soils and Foundations, vol. 28, no. 4, pp. 107-118.

Mao, X \& Fahey, M 1999, 'A method of reconstituting an argonite soil using a synthetic flocculant', Géotechnique, vol. 49, no. 1, pp. 15-32.

McPhail, G, Noble, A, Papageourgiou, G \& Wilkinson, D 2004, 'Development and implementation of thickened tailings discharge at Osborne Mine, Queensland, Australia', in RJ Jewell \& AB Fourie (eds), Paste 2004: Proceedings of the 7th International Seminar on Paste and Thickened Tailings, Australian Centre for Geomechanics, Perth.

Reid, D 2019, 'Estimating the in situ state of a thickened tailings deposit', in A Paterson, AB Fourie \& D Reid (eds), Paste 2019: Proceedings of the 22nd International Seminar on Paste and Thickened Tailings, Australian Centre for Geomechanics, Perth, pp. 95-106.

Reid, D 2021, 'Some considerations on the engineering performance of subaqueously-deposited silts', Proceedings of Mine Waste Tailings 2021, The Australasian Institute of Mining and Metallurgy, Melbourne.

Reid, D, Fanni, R, Koh, K \& Orea, I 2018, 'Characterisation of a subaqueously deposited silt iron ore tailings', Géotechnique Letters, vol. 8, no. 4, pp. 278-283.

Reid, D \& Fanni, R 2020, 'A comparison of intact and reconstituted samples of a silt tailings', Géotechnique, ahead of print, https://doi.org/10.1680/jgeot.20.P.020

Reid, D, Fanni, R \& Fourie, A 2021, 'Effect of tamping conditions on the shear strength of tailings', International Journal of Geomechanics, under review.

Reid, D \& Fourie, AB 2014, 'Assessing the post-liquefaction shear strength of thickened tailings in the design stage - a review and update', in RJ Jewell, AB Fourie, PS Wells \& DV Van Zyl (eds), Paste 2014: Proceedings of the 17th International Seminar on Paste and Thickened Tailings, Australian Centre for Geomechanics, Perth, pp. 429-444. 
Reid, D \& Fourie, AB 2015, 'The influence of slurry density on in situ density', in RJ Jewell \& AB Fourie (eds), Paste 2015: Proceedings of the 18th International Seminar on Paste and Thickened Tailings, Australian Centre for Geomechanics, Perth, Australia, pp. 95-106.

Reid, D \& Fourie, AB 2016, 'Laboratory assessment of the effects of polymer treatment on geotechnical properties of a low-plasticity soil slurry', Canadian Geotechnical Journal, vol. 53, no. 10, pp. 1718-1730.

Reid, D \& Fourie, AB 2017, 'Effects of polymer treatment on undrained strengths and cyclic behaviour of a low-plasticity slurry', Journal of Geotechnical and Geoenvironmental Engineering, vol. 143, no. 6.

Reid, D \& Fourie, AB 2018a, 'Centrifuge assessment of the effects of polymer treatment on penetrometer response', International Journal of Physical Modelling in Geotechnics, vol. 18, no. 5, pp. 240-252.

Reid, D \& Fourie, AB 2018b, 'Geotechnical effects of polymer treatment on tailings - state of knowledge review', in RJ Jewell \& AB Fourie (eds), Paste 2018: Proceedings of the 21st International Seminar on Paste and Thickened Tailings, Australian Centre for Geomechanics, Perth, pp. 263-276.

Reid, D, Fourie, AB, Ayala, JL, Dickinson, S, Ochoa-Cornejo, F, Fanni, R, Garfias, J, Viana da Fonseca, A, Ghafghazi, M, Ovalle, C, Riemer, M, Rismanchian, A, Olivera R \& Suazo, G 2020, 'Results of a critical state line test round robin program', Géotechnique, in press.

Reid, D, Fourie, AB \& Moggach, S 2019, 'Characterization of a gold tailings with hypersaline pore fluid', Canadian Geotechnical Journal, vol. 75, no. 4, pp. 482-496.

Reid, D \& Jefferies, MG 2017, 'State parameter as a geological principle in tailings', in GW Wilson, DC Sego \& NA Beier (eds), Proceedings of Tailings and Mine Waste 2017, University of Alberta, Edmonton, pp. 305-314.

Reid, D \& Jefferies, MG 2018, 'A geological principle for the density of thickened tailings', in RJ Jewell \& AB Fourie (eds), Paste 2018: Proceedings of the 21st International Seminar on Paste and Thickened Tailings, Australian Centre for Geomechanics, Perth, pp. 117-126.

Shuttle, DA \& Cunning, J 2007, 'Liquefaction potential of silts from CPTu', Canadian Geotechnical Journal, vol. 44, pp. 1-7.

Sladen, JA \& Handford, G 1987, 'A potential systematic error in laboratory testing of very loose sands', Canadian Geotechnical Journal, vol. 24, no. 3, pp. 462-466.

Wang, S, Luna, R \& Stephenson, R 2011, 'A slurry consolidation approach to reconstitute low-plasticity silt specimens for laboratory triaxial testing', Geotechnical Testing Journal, vol. 34, no. 4, pp. 288-296. 
